\title{
RISK FACTORS FOR PREMATURE BIRTH IN FRENCH GUIANA: The importance of reducing health inequalities
}

Malika Leneuve-Dorilas, Anne Favre, Gabriel Carles, Alphonse Louis \& Mathieu Nacher

\section{ABSTRACT}

French Guiana has the highest birth rate in South America. This French territory also has the highest premature birth rate and perinatal mortality rate of all French territories.

The objective was to determine the premature birth rate and to identify the prevalence of risk factors of premature birth in French Guiana.

A retrospective study of all births in French Guiana was conducted between January 2013 to December 2014 using the computerized registry compiling all live births over 22 weeks of gestation on the territory.

During this period 12983 live births were reported on the territory. $13.5 \%$ of newborns were born before 37 WG (1 755/12 983). The study of the registry revealed that common sociodemographic risk factors of prematurity were present. In addition, past obstetrical history was also important : a scarred uterus increased the risk of prematurity adjusted odds ratio=1.4. 95\%CI [1.2-1.6]). Similarly, obstetrical surveillance, the absence of preparation for birth or of prenatal interview increased the risk of prematurity by 2.4 and 2.3 , the excess fraction in the population was $69 \%$ and $72.2 \%$, respectively.

Known classical risk factors are important. The present study allowed to calculate excess fractions in order to prioritize interventions to reduce the prematurity rate. 
In most industrialized countries. prematurity has increased during the past 3 decades.(1)

In these countries. 5 to $11 \%$ of children are born before term $(<37$ weeks of amenorrhea (WA)). with an increasing rate since the early 1980's.(2)

The frequency of premature labor is estimated between 12 and $13 \%$ in the USA and between 5 and $7 \%$ in Europe.(3) Premature births are important contributors to neonatal morbidity and mortality. and are the cause of nearly $50 \%$ of perinatal handicaps which. in France. represents 3500 children each year.(3)

Whether prematurity is spontaneous or induced. it is presently admitted that its causes are heterogeneous. Certain studies have listed several risk factors such as maternal age $<18$ years. addictions. low educational level. low socio-economic level. single parenthood. black populations. low body mass index. parodontal disease. a low intergenesic interval. prior prematurity. and multiple pregnancies.

Certain obstetrical complications are strongly associated with prematurity such as hypertension and pre-eclampsia, diabetes. general or loco-regional infection.(1) (4) (5) (6) (7)

There are marked disparities between mainland France and French overseas territories French Guiana. Guadeloupe and Reunion island. According to the national perinatal survey in 2010. these disparities are particularly marked for prematurity with a twofold increase in French overseas territories relative to mainland France : $7.4 \%$ in mainland France versus $15.4 \%$ in the overseas territories (out of 514 births in the overseas territories for this study). (8)

Situated on the North Eastern part of the South American continent $7100 \mathrm{~km}$ from Paris, French Guiana has an ethnically and socioeconomically diverse population of 250000 persons living on a $83846 \mathrm{~km}^{2}$ territory (the size of Portugal) (9). On average, there are 6500 births per year (26 per 1000 and $88 \%$ of births out of wedlock) which makes it the French territory with the second highest birth rate after Mayotte and the highest birth rate in South America. In French Guiana there is one level III obstetrics ward, and 2 level II wards. Given the marked isolation of certain towns that can only be accessed by air or by boat, there are 23 mother and child care centers and 21 health centers that are administered by Cayenne hospital. In these structures, midwives are not present full time and deliveries cannot guaranty the safety of the mother and newborn child. Thus, since 1994 itinerant obstetrical consultations have been organized and in utero transfers to the nearest hospital have become policy. Women are transferred at a term of 37 weeks in order to deliver in a hospital, and if there is any obstetrical pathology women are transferred to the sole level III obstetrical ward of French Guiana, located in Cayenne.

The pregnancy outcome registry was created in 1992 and allowed to quantify premature births on the territory of French Guiana. Since its creation the registry has shown a stable proportion of premature births in French Guiana around $13.5 \%$ which is nearly double the $7 \%$ reported in mainland France (10) .

Apart from known risk factors, French Guiana also has specificities that may explain this higher prematurity rate: unemployment (a quarter of the active population has no employment), insufficient pregnancy surveillance, the frequency of teen pregnancies ( $7 \%$ of 
all births), the frequency of anemia with $70 \%$ of pregnant women concerned in Western French Guiana, and dengue epidemics.(11)

The relative impact of the above factors results from a combination of their frequency and the strength of their link with prematurity. The relative ranking of these factors is not known in French Guiana. Given the numerous particularities of the territory, and given the absence of reduction of the prematurity rate, the present study aimed to determine the risk factors of prematurity in French Guiana and to obtain excess fractions in order to help identify priorities in order to reduce the high prematurity rate.

\section{METHODS}

Study site. This retrospective study took place in all health structures in French Guiana.

Data collection. The exhaustive data from the delivery registry (RIGI (Registre d'Issue de Grossesses Informatisé managed by the Reseau Perinat, a network of health professionnals around perinatality)) was studied for a period of 2 years from January first 2013 to December $31^{\text {st }}$ 2014. Premature births occurring after the 22 WA fetal viability threshold were tallied. The data was entered in the delivery wards by the midwives who deliver the babies. The data management was performed by the mother and child care (PMI) center and the health regional agency.

\section{Recommendations for pregnancy follow up in French Guiana}

In France, seven prenatal visits are recommended, one of which should be in the first trimester, then followed by one visit every month after the third trimester. Three obstetrical ultrasonographies are recommended during the follow up, one at each trimester.

A prenatal interview is systematically proposed either individually or as a couple during the first trimester of pregnancy. This prenatal interview is recommended by the Health authorities since 2005. This interview is not a medical obstetrical consultation. The objective of this interview is to identify vulnerability situations and to orient women towards specialized support, to give information on risk factors, risk behaviours, and nearby resources.(6)

Preparation for birth was historically focused on relieving pain. However, it is now oriented towards global accompaniment of women and couples. In France, 8 prenatal sessions are reimbursed by health insurance. The preparation for birth has the objective of letting women express their needs, to evaluate parental knowledge, to explain the course of pregnancy, delivery and post partum. It contributes to the identification of early symptoms and warning signs that should motivate an urgent consultation. (12)

\section{Data analysis}

A descriptive analysis was first performed looking at each variable individually (distribution. summary statistics) then cross tabulating pertinent variables. Births were classified as premature or not. The distribution of medical or socioeconomic variables was studied across the groups defined by the main outcome. Qualitative variables were compared using a Chi square test or Fischer's exact test where appropriate. Quantitative variables were compared using Student's t-test or non parametric tests when variables where non Gaussian or if variances were heteroscedastic. Crude odds ratios and adjusted odds ratios were computed using prematurity as the outcome variable and different predictors as independent variables. Although attributable fractions are often used for causal biological exposures, they may also be computed for retrospective studies that cannot prove causation. (13) In this context where causation cannot be firmly established, it has been suggested that excess fraction should be 
used instead of attributable fraction. (14) Thus, excess fractions in the exposed and in the population were computed in order to determine the most important variables. Multivariate analysis was performed to adjust for potential confounding. The variables selected in the model were those known to be associated with prematurity in the medical literature and those significantly linked in the bivariate analysis. The statistical significance threshold was $\mathrm{p}<0.05$. The data was analyzed with $\mathrm{R}$ and Stata.

Regulatory and ethical aspects. The data base has been approved since 1992 by the Commission Nationale Informatique et Libertés, the French Structure that overseas medical research data and projects.

\section{RESULTS}

\section{Socio-demographic data}

From January 2013 to December 2014, 12983 births > 22 WA were notified in French Guiana.

The mean age of the study population was 27.5 years (median 27 years, range 12 - 52 years). Minors ( $<18$ years) represented $6.2 \%$ of the study population $(803 / 12983)$ and women over 40 years. $4.5 \%$ (588/12 983).

The natives of French Guiana were the most represented population, 40.6\% (5 266/12 983). followed by Surinamese 22.2\% (2 888/12 983) and Haitian nationals 12.9\% (1 679/12 983). Brazilian natives represented $8 \%$ of the study population (1 038/12 983).

The surface of French Guiana being covered by $90 \%$ of equatorial forest, populations living in the interior face relative isolation from health and social structures. Figure 1 shows the map of the administrative origin of women in the Study:

- Central Coastal in green (6 communes) represents $43.6 \%$ of the study population (5 660 births/12 983),

- Western French Guiana in blue (8 communes), 40.8\% of births (5 296/12 983),

- Eastern French Guiana in brown (4 communes), 3\% of births (388/12 983),

- Savannas in red (4 communes), 10.5\% of births (1 364/12 983),

- Others, 2,1\% (275/12 983).

Details regarding the residence location of the study population are necessary, because this criterion could be associated with some risk factors for prematurity.

Regarding the profession of the study population; 68.5\% (8 899/12 983) of subjects had no profession, other professional categories are presented in table 2.

Over 50\% (7 421/12 $983(57.2 \%)$ ) of the population had general health insurance, but $9.3 \%$ (1 211/12983) had no health coverage at all.

\section{Medical data}


During the study period, premature births represented 13.5\% (1 755/12 983) of all births. Of these, spontaneous prematurity represented $51.3 \%$ (901/ 1755) of premature births versus $48.7 \%$ (854/ 1755 ) induced prematurity (labor induction or elective cesarean section).

Premature births range from:

- Very extreme preterm birth < 25 WA representing $0.5 \%$ of births $(69 / 12983)$;

- Extreme preterm [25-27 WA] representing 0.9\% of births (111/12 983);

- Very preterm [28-32 WA]. 2.3\% of births (295/12 983);

- $\quad$ And moderate preterm [33-36 WA], 9.9\% (1280/12 983).

Table 2 describes the obstetrical profile of patients and elements relative to pregnancy follow up and events having occurred during pregnancy. The first column lists the studied variables.

\section{Risk factors for prematurity}

Table 1 shows the prematurity risk factors. Being under 18 years was associated with preterm delivery in the bivariate analysis but not in the multivariate. However, when looking at younger age groups ( $<16$ years) a young age was associated with an increased risk of prematurity $\mathrm{AOR}=1.5[95 \% \mathrm{CI}=1.02-2.12], \mathrm{p}=0.04$.

On the study sample, age was associated with preterm birth. Although $16.1 \%$ of those $<18$ years delivered prematurely, this was not significantly associated with prematurity in the multivariate model. Having an age 40 and above was significantly associated with preterm birth.

The mother's birth place was significantly associated with preterm birth in the bivariate analysis, with women born in Suriname at greater risk of preterm delivery $\mathrm{OR}=1.5,95 \% \mathrm{CI}=$ [1.1-2]. The place of residence was also a significant risk factor for preterm birth $(\mathrm{p}<0.0001)$, after adjusting for age, birth place, family situation, profession and health insurance situation. The generation of an interaction term between Suriname and Saint Laurent du Maroni (where most Surinamese women are seen) was not significantly associated with the outcome in the multivariate model and was thus removed from the final model.

Table 2 shows the medical and obstetrical risk factors for premature delivery.

Grand multigravida and grand multipara were significantly linked to preterm birth in the bivariate analysis $\mathrm{OR}=1.2[95 \% \mathrm{CI}=1.1-1.3]$ and $1.3[95 \% \mathrm{CI}=1.2-1.5]$.

An early pregnancy follow up with a first prenatal visit during the first trimester was associated with a lower risk of preterm delivery in the bivariate analysis. Similarly, having benefitted from preparation for birth programme, and a prenatal interview were associated with a lower risk of premature birth. 
Table 3 shows the prevalence of various pathologies among the studied women and their associated risk factors for premature delivery, with preeclampsia the pathology with the highest crude and associated odds ratios.

Table 4 shows the crude excess fractions in the exposed and in the population.

The absence of prenatal interview and the absence of preparation for birth had by far the highest excess fractions among the explored risk factors. 


\section{DISCUSSION}

The present study identified a number of predictors of premature delivery in French Guiana. Most of these predictors are known risk factors for premature delivery. Here, in the special context of French Guiana we used excess fractions to rank the factors in terms of their potential impact, and their changeability. Thus the main message from this analysis would be that most of the progress against premature delivery could be achieved by proper follow up of pregnancy, a message that is both encouraging and challenging given the social and geographical complexity of French Guiana.

\section{Socio-demographic factors}

French Guiana has a cosmopolitan population. Apart from common risk factors for prematurity, there have been reports of a higher risk of prematurity among the population of African ancestry. (6) (7). A study in the USA showed that the risk of premature delivery was 3 times higher in the African-American population than in the Caucasian population. The study showed that socioeconomic factors were important but could not completely explain the excess prematurity in the black population. (6) Here mothers born in French Guiana (mostly creole) had a higher risk of premature delivery than mothers born in mainland France (mostly Caucasian). This may have reflected more frequent preterm deliveries linked to African ancestry however, despite the plausibility of this explanation, ancestry was not available. Moreover, despite adjustments for potential confounders, there may have been residual confounding explaining these differences

In addition, the overseas French territories are the areas were teen pregnancies are most frequent in France. In the Réunion Island, teen pregnancies represent $3.8 \%$ of births, in the French Antilles it represents $2.8 \%$ versus $6.2 \%$ in French Guiana.(15) (16)

In Mainland France this rate has been $<1 \%$ for over 10 years, fluctuating around $0.8 \%$. (17)

Overall $6.2 \%$ of the population was minor. Women $<18$ years had increased premature delivery 1.2 fold but after adjustments this was no longer significant. However, after adjustment for potential confounders, there was a significant link between preterm birth and age $<16$ years AOR $=1.5$ (95\% CI [1.02-2.12], $\mathrm{p}=0.04$. Another study conducted in western French Guiana has however shown a significant association between pregnancies $<15$ years of age and preterm delivery after adjustment for potential confounders. (18)

Social and behavioural elements such as pregnancy denial or concealment from one's family and late consultation may have confounded the link with being under 18 years of age. (15)

Other studies in Sudan, Saudi Arabia and Nigeria have also found conflicting results regarding the influence of teen pregnancies on premature delivery. (19)

In addition to teen pregnancy, social determinants of health are particularly important in French Guiana. 
In 2014, the unemployment rate was $22.3 \%$ in French Guiana versus $9.9 \%$ in mainland France. (ref INSEE_Institut national de la statistique et des études économiques).

Here $68.5 \%$ of the population was without profession (88 99/12 983). The employment rate in French Guiana for 2014 was $46.2 \%$ which was much lower than the $64.3 \%$ in mainland France (ref INSEE).

In addition to unemployment, precariousness is linked to income, family ties, housing... In 2011, poverty affected an estimated 87000 persons in French Guiana, which represents a poverty rate of $44.3 \%$. This rate is much higher than in other French territories, such as Guadeloupe (19.4\%), Martinique (21.1\%), or mainland France (14.3\%).(18)

The proportion of households living on welfare reaches $23.4 \%$ versus $5.1 \%$ in Mainland France. These social conditions are known risk factors for poor pregnancy follow up and increased obstetrical complications, notably preterm births. (20) (21) (22)

In 2008, a study on 1444 women revealed that for 1057 women for whom the number of consultations was available, $24.6 \%$ had a late first consultation $\left(2^{\text {nd }}\right.$ or $3^{\text {rd }}$ trimester $)$ and $43.9 \%$ had less than 7 prenatal consultations versus $8.5 \%$ in mainland France. A study of 1057 women conducted in French Guiana showed that $46.5 \%$ of pregnant women had a late first obstetrical consultation (between the second and the third trimester of pregnancy) and that $32.4 \%$ of them had had less than the 7 recommended prenatal consultations versus $8.5 \%$ in mainland France.(23)

In the present study, after adjusting for health insurance, family situation, age, and pregnancy follow up patients without a job were significantly more likely to have preterm delivery. When looking at excess fractions, $24.2 \%$ of premature delivery in unemployed women could be linked to unemployment. Among these women prenatal follow up was generally insufficient. In the general population of pregnant women $17.8 \%$ of preterm deliveries were attributable to the absence of professional activity.

Access to rights thus seems to be a crucial element to reduce preterm deliveries.(24)

Health insurance for those in a precarious situation (Universal coverage, state medical aid) was associated with a reduction in the risk of preterm birth and conversely absence of health insurance was independently associated with preterm birth. (6)

Apart from these common sociodemographic criteria, the place of residence was associated with preterm delivery. Women living in western French Guiana had a significantly increased odds of preterm birth. An ongoing study in Western French Guiana showed that $24.1 \%$ of 529 pregnant women had increased lead concentration $(>50 \mu \mathrm{g} / \mathrm{dl})$. Although professional and environmental 
exposures have been considerably reduced, adverse obstetrical consequences have also been observed for lead blood concentrations deemed «acceptable» $(\leq 10 \mu \mathrm{g} / \mathrm{dl})$. (25) (26)

In addition, in Western French Guiana, apart from women with sickle cell anemia, the prevalence of anemia in pregnant women is $70 \%$ (27), which can also contribute to the increase of preterm delivery. (28) (29)

The Maroon population, living mostly in French Guiana, may also have an increased risk of preterm delivery for ethnic or geographical reasons. Further investigations measuring the concentration of lead, mercury (linked to gold mining in the region) and other environmental toxics may be useful to better disentangle the determinants of this increase of preterm births in Western French Guiana.(26)

\section{Medical obstetrical factors}

As described by others (30). primiparous women had a higher risk of preterm delivery after adjustment for potential confounders. (4)

After adjustment for potential confounders, multiparity was not associated with preterm delivery. Thus, more than the actual number of pregnancies, it was the specific obstetrical events, which are more frequent in those with multiple pregnancies, that were associated with preterm delivery. A scarred uterus, notably caesarian section during the second phase of labor subsequently increased the risk of preterm delivery. (31)

Finally, as emphasized by the excess fractions, pregnancy follow up has a major importance to prevent preterm delivery with among women giving premature births would explain $59 \%$ of prematurity and $7.5 \%$ in the total population of pregnant women. Excess fractions should not be viewed here as biological constants but as reflecting the studied population and the specific distribution of other covariables influencing the outcome in French Guiana. (14) In the context of French Guiana, the absence of preparation for birth and prenatal interview were thus identified as major risk factors with excess fractions in the population of 69 and $72.2 \%$ respectively, which is far greater than any other risk factor. Thus if the health system aims to reduce preterm birth, the study of excess fractions points towards a very pragmatic intervention: improving the follow up of pregnant women, notably those who are most socially vulnerable.(32)

More generally, beyond the context of French Guiana, studies on predictors of preterm delivery could also use excess fractions to better rank risk factors within each population in order to identify intervention priorities. As emphasized by the World Health Organization in 2012, midwives have a major role in prevention, screening for complications and follow up of pregnant women, in developed and in developing countries. Their role spans the course of pregnancy but also may concern minors before pregnancy or women well after 28 days post partum. A 2014 review compiled over 50 outcomes that could be improved by midwives among which preterm birth, with a more efficient use of resources when provided by properly trained midwives, thus supporting a system-level shift from care focused on identification and treatment of pathology for a minority of women to skilled care for all women. In the 
context of the low medical density the high frequency of obstetrical complications, and perinatal deaths in French Guiana there is definitely an important place for more midwives, notably for prevention in the remote areas with the aim of reducing preterm birth in the most vulnerable women.

\section{CONCLUSION}

Given the slow reduction of perinatal mortality and French Guiana (10) and the high burden of prematurity (comparable to some African countries(32) ) and its relative stagnation, it is crucial to devise targeted interventions with maximum impact. The present study has shown the predictive factors of prematurity in French Guiana and has allowed to rank them in terms of expected impact. Although there is no magic bullet, the present results point for a very obvious intervention: improving the follow up of the poorest pregnant women.

Given the saturation of the obstetrical professionals, this may require further outreach mechanisms and specific funding to change health-seeking behavior, improve access to care to reduce social inequalities of health.

\section{DECLARATION OF INTERESTS}

The authors declare no conflict of interest regarding this study. 


\section{REFERENCES}

1. Lacroze V. Prématurité : définitions, épidémiologie, étiopathogénie, organisation des soins. Elsevier Massons SAS, Paris, Pédiatrie. 2011; 4-002-N-10.

2. Wen SW, Smith G, Yang Q, Walker M. Epidemiology of preterm birth and neonatal outcome. Seminars in Fetal and Neonatal Medicine. 2004 décembre;9(6):429-35.

3. Ancel P-Y. Une fréquence en augmentation: Épidémiologie de la prématurité. La Revue du praticien. 2012;62(3):362-5.

4. Goldenberg RL, Culhane JF, Iams JD, Romero R. Epidemiology and causes of preterm birth. The Lancet. 2008 Jan 11;371(9606):75-84.

5. Passini Jr R, Tedesco RP, Marba ST, et al. Brazilian Multicentre Study on Preterm Birth (EMIP): Prevalence and Factors Associated with Spontaneous Preterm Birth. BMC Pregnancy and Childbirth. 10;22:2.

6. Ehrenthal DB, Jurkovitz C, Hoffman M, Kroelinger C, Weintraub W. A population study of the contribution of medical comorbidity to the risk of prematurity in blacks. American Journal of Obstetrics and Gynecology. 2007 Oct;197(4):409.e1-409.e6.

7. MacDorman MF. Race and Ethnic Disparities in Fetal Mortality, Preterm Birth, and Infant Mortality in the United States: An Overview. Seminars in Perinatology. 2011 août;35(4):200-8.

8. Direction de la Recherche. des études. de l'évaluation et des Statistiques (DREES). La situation périnatale en France en 2010 - Premiers résultats de l'enquête nationale périnatale - Etude et résultats. 2011;

9. Montabo B. Le grand livre de l'histoire de la Guyane: Des origines à 1848. Orphie; 2004. 336 p.

10. Cardoso T, Carles G, Patient G, Clayette P, Tescher G, Carme B. Périnatalité en Guyane française: Evolution de 1992 à 1999. Journal de gynécologie obstétrique et biologie de la reproduction. 2003;32(4):345-55.

11. Basurko C, Carles G, Youssef M, Guindi WEL. Maternal and foetal consequences of dengue fever during pregnancy. European Journal of Obstetrics \& Gynecology and Reproductive Biology. 2009 Nov;147(1):29-32.

12. Haute Autorité de Santé (HAS). Préparation à la naissance et à la parentalité. Recommandations professionnelles. 2005; Available from: http://www.hassante.fr/portail/upload/docs/application/pdf/preparation_naissance_recos.pdf

13. Taylor JW. Simple Estimation of Population Attributable Risk from Case-Control Studies. Am J Epidemiol. 1977 Oct 1;106(4):260-260.

14. Greenland S, Robins JM. Conceptual problems in the definition and interpretation of attributable fractions. Am J Epidemiol. 1988 Dec;128(6):1185-97. 
15. Guiot O, Foucan T, Janky E, Kadhel P. Grossesses évolutives chez les mineures en Guadeloupe : nouvel état des lieux. Journal de Gynécologie Obstétrique et Biologie de la Reproduction. 2013 juin;42(4):372-82.

16. Institut National de la Statistique et des Etudes Economiques (INSEE). ANTIANE ECO : La revue économique et sociale des Antilles-Guyane. 2011 Juillet. nº74:39.

17. Alouini S, Randriambololona D, Randriamboavonjy R. Facteurs de risques de la grossesse, de l'accouchement et du post-partum des adolescentes dans le département du Loiret. Journal de Gynécologie Obstétrique et Biologie de la Reproduction. 2015 mai;44(5):443-50.

18. Soula O, Carles G, Largeaud M, El Guindi W, Montoya Y. Grossesses et accouchement chez les adolescentes de moins de 15 ans: Étude de 181 cas en Guyane française. Journal de Gynécologie Obstétrique et Biologie de la Reproduction. 2006 Jan;35(1):53-61.

19. Adam GK, Elhassan EM, Ahmed AM, Adam I. Maternal and perinatal outcome in teenage pregnancies in Sudan. International Journal of Gynecology \& Obstetrics. 2009 mai;105(2):1701 .

20. Lejeune C. Précarité et prématurité. Journal de Pédiatrie et de Puériculture. 2008 décembre;21(8):344-8.

21. Convers M. Utilisation du score Épices pour repérer la précarité et optimiser la prise en charge de la grossesse. La Revue Sage-Femme. 2010 février;9(1):3-9.

22. Gayral-Taminh M, Daubisse-Marliac L, Baron M, Maurel G, Rème J-M, Grandjean H. Caractéristiques socio-démographiques et risques périnatals des mères en situation de précarité. Journal de Gynécologie Obstétrique et Biologie de la Reproduction. 2005 février;34(1):23-32.

23. Rapport d'étude Malinguy. Frequence, Determinants Et Consequences Du Mauvais Suivi Des Grossesses En Guyane Francaise. 2008; Available from: http://www.crpv-guyane.org/wpcontent/uploads/2015/04/Rapport-etudes-Malinguy.pdf

24. Giami I. Chapitre 80 - Précarité et périnatalité. In: Marpeau L, editor. Traité d'obstétrique. Paris: Elsevier Masson; 2010. p. 619-23.

25. Vigeh M, Yokoyama K, Seyedaghamiri Z, et al. Blood lead at currently acceptable levels may cause preterm labour. Occup Environ Med. 2010 Aug 26;oem.2009.050419.

26. Kapoor N, Tiwari P. Effects of heavy metal poisoning during pregnancy. International Research Journal of Environment Sciences. International Research Journal of Environment Sciences. 2013 Jan; $\operatorname{vol}(1): 88-9$.

27. Louison-Ferte A, Jolivet A, Lambert V, Bosquillon L, Carles G. Lutte contre l'anémie de la femme enceinte dans l'Ouest Guyanais : diagnostic et mise en œuvre d'actions par le Réseau Périnat Guyane autour d'une évaluation des pratiques professionnelles. Revue de médecine périnatale. 2014 Juin;vol. 6. Issue $2: 117$. 
28. Beucher G, Grossetti E, Simonet T, Leporrier M, Dreyfus M. Anémie par carence martiale et grossesse. Prévention et traitement. La Revue Sage-Femme. 2011 Sep;10(4):152-67.

29. Levy A, Fraser D, Katz M, Mazor M, Sheiner E. Maternal anemia during pregnancy is an independent risk factor for low birthweight and preterm delivery. European Journal of Obstetrics \& Gynecology and Reproductive Biology. 2005 Oct 1;122(2):182-6.

30. Weaver EH, Gibbons L, Belizán JM, Althabe F. The increasing trend in preterm birth in public hospitals in northern Argentina. International Journal of Gynecology \& Obstetrics. 2015 août;130(2):137-41.

31. Levine LD, Sammel MD, Hirshberg A, Elovitz MA, Srinivas SK. Does stage of labor at time of cesarean delivery affect risk of subsequent preterm birth? Am J Obstet Gynecol. 2015 Mar;212(3):360.e1-7.

32. Howson EDS CP, Kinney MV, Lawn JE. Save the Children. WHO. Born Too Soon: The Global Action Report on Preterm Birth. World Health Organization. Geneva; 2012; 